\title{
A MODEL TO COMPARE A DEFINED BENEFIT PENSION FUND WITH A DEFINED CONTRIBUTION PROVIDENT FUND
}

\author{
J. M. NEVIN and J. SWART \\ Department of Mathematics and Applied Mathematics \\ University of Natal \\ Pietermaritzburg \\ South Africa
}

\begin{abstract}
During 1994 universities and certain other institutions were given the option of setting up private retirement funds as an alternative to the AIPF. Because of the underfundedness of the AIPF only a substantially reduced Actuarial Reserve Value could be transfered to the new fund on behalf of each member. Employees at these institutions had to make the difficult decision of whether to remain a member of the AIPF or to join a new fund. Several institutions created defined contribution funds as an alternative to the AIPF. In such funds the member carries the investment risk and most institutions felt the need to provide some form of top-up of the Transfer Value. A simple mathematical model is formulated to aid in the comparison of expected retirement benefits under the AIPF and a private fund and to investigate the management problem of distributing additional top-up funds in a fair manner amongst the various age groups within the fund.
\end{abstract}

\section{INTRODUCTION}

Privatisation of State Pension Funds has been under review since 1989. Investigations by the Robson- and Korsten Commissions resulted in legislation being passed (Government Gazette, 22 April 1994) enabling participating institutions to withdraw from the state-run Associated Instituitions Pension Fund (henceforth known as AIPF) and to set up their own funds. Institutions such as the universities were given a December 1994 deadline to consider the setting up of funds as alternatives to the AIPF. 
Because of the underfundedness of the AIPF, participating institutions have had to increase their contributions on behalf of employees over the years from twice as much as the employee contribution to 2,74 times as much. It was therefore in the interest of such institutions to set up viable alternatives as they had no control over possible further increases in their contributions to the AIPF.

The AIPF is a defined benefit fund. The benefit consists of a tax-free lump sum (the gratuity) and a taxable pension (the annuity). The value of the gratuity and the value of the annuity in the first year of retirement is defined in the rules by means of a formula which depends only on the member's final salary and length of pensionable service. The annuity may increase annually after retirement by an amount which is not guaranteed but which has historically been set at about $70 \%$ of the inflation rate. The investment risk rests entirely with the state. It is possible that poor investment performance in the future may affect the annual pension increases. However, in the past employers have been asked to increase their contributions in order to meet payouts.

In contrast, the performance of a defined contribution fund depends entirely on the underlying investments and the risk rests with the member. In the case of a provident fund a member may at retirement elect to receive between $0 \%$ and $100 \%$ of the retirement capital as a lump sum, the remainder will be converted into a pension.

During the course of 1994 it was learned that the funding level (the ratio of assets to liabilities) of the AIPF was only some $60 \%$, so that the so-called Transfer Values received from the AIPF would be short of the Actuarial Reserve Value by approximately $40 \%$. From a survey conducted by us, it is apparent that most, if not all, universities set up private provident or pension funds as alternatives to the AIPF and that the vast majority of employees joined the new funds. Institutions that opted for defined benefit funds tended to offer benefits very similar to those of the AIPF, with the institution now carrying the risk of meeting the anticipated claims. Institutions that opted for defined contribution funds often created retirement reserve funds on behalf of some or all of their employees to make up some of the shortfall. Certain institutions offered their 
employees the choice between a defined benefit fund and a defined contribution fund and in such cases it would be unusual to offer any top-up to employees choosing the latter option.

We are interested in comparing the expected retirement benefits offered by the AIPF with those of a defined contribution provident fund, and develop a model to compare the after tax benefits of the AIPF with those of the provident fund, allowing for the fact that the member may enjoy some form of top-up (retirement reserve). On retirement from the AIPF, the entire lump sum (gratuity) is tax-free whereas the tax-free amount from a provident fund consists of The Transfer Value from the AIPF, excluding investment growth in the new fund, together with an amount which in most cases is the greater of R120000 and R4500 × number of years of pensionable service (see section 2.4). Intuitively it may be felt that strong fund performance (say $4 \%$ or more above salary inflation) should make up some or all of the shortfall in Transfer Values for those with more than say 10 years to retirement. However, the effects of taxation are not obvious. Average tax rates for university professors or their equivalents, are of the order of $40 \%$ which is the same as the alleged shortfall in AIPF funding, the AIPF gratuity is currently tax-free, while an increasing fraction of the provident lump sum will attract tax over the years. Hence it is immediately obvious that a model is necessary to compare the after-tax benefits of the two cases for various age groups.

We will use the model to investigate the level of the top-up required under various reasonable assumptions on parameter values, in order that a well managed provident fund may equal the retirement benefits of the AIPF and will look at the management problem of distributing available funds in a fair manner over the age groups of members.

Provident funds allow for more flexibility and are likely to offer benefits greater than those offered by the AIPF for members leaving the fund for reasons other than retirement. When these factors are taken into account it may well be that one is satisfied with a retirement benefit of below $100 \%$ of the equivalent AIPF benefit. 
Finally we should mention that the model can obviously be adapted to deal with defined benefit funds other than the AIPF.

\section{THE MODEL}

In this section we formulate a model in order to compare the benefits offered under the two schemes. In 2.1 we derive a preliminary formula that is applicable to any escalating annuity. In 2.2 we define the parameters which will affect the relative performances of the AIPF and a defined contribution fund. In 2.3-2.5 we calculate the after-tax lump sum equivalent to the AIPF annuity, add that to the AIPF gratuity (which is tax-free) and compare the resulting lump sum with the after-tax lump sum of the provident fund.

\subsection{After-tax capital equivalent of an escalating annuity}

Suppose an individual has to choose between the following two options:

1. receiving an annuity which runs for a term of $L$ years, has an initial payment of A rands per annum, escalates at a constant rate of a per annum and is fully taxable.

2. receiving an after-tax lump sum $P$ which may be freely invested to provide income over the period $\mathrm{L}$.

We will find the value of $P$ in order that the two options are equivalent in the sense that they provide the same after-tax income over the period L. In option 1 , the annuity payments are

$$
A, A(1+a), \ldots, A(1+a)^{L-1}
$$

so that the after-tax income provided in the $m$ th year is

$$
A(1+a)^{m-1}(1-\alpha)
$$

where $\alpha$ is the average tax-rate on the annuity income $(m=1,2, \ldots, L)$.

In option 2 we divide the amount $P$ into $L$ parts, one for each year 


$$
P=P_{1}+P_{2}+\cdots+P_{L}
$$

with the intention that $P_{m}$ will be invested for $m-1$ years and in the $m$ th year it will be cashed in to provide the income for that year. Suppose that the annual after-tax rate of increase on investments is $b$, so that the after-tax value of $P_{m}$ after $m-1$ years is

$$
P_{m}(1+b)^{m-1}
$$

For the equivalence of the two options we thus require

$$
P_{m}(1+b)^{m-1}=A(1+a)^{m-1}(1-\alpha)
$$

or

$$
P_{m}=\frac{A(1-\alpha)(1+a)^{m-1}}{(1+b)^{m-1}}
$$

Writing $x=\frac{1+a}{1+b}$, we have $P_{m}=A(1-\alpha) x^{m-1}$ and

$$
\begin{aligned}
P=A & (1-\alpha)\left(1+x+x^{2}+\cdots+x^{L-1}\right) \\
= & A(1-\alpha)\left(\frac{1-x^{L}}{1-x}\right)
\end{aligned}
$$

$P$ is the after-tax capital equivalent of the escalating annuity and may also be called the present value after tax of the escalating annuity. It is of interest to note that the value of the power function $\frac{1-x^{L}}{1-x}$ depends, to within a few percent, only on $b-a$ and not on the individual values of $a$ and $b$ (see the appendix). The power function can be closely approximated by a quadratic in $\mathrm{b}-\mathrm{a}$ and it is a decreasing function of $\mathrm{b}-\mathrm{a}$. This means that small values of $b$-a will lead to relatively better benefits under the AIPF than larger 
ones and may well imply that only those confident of earning high returns $b$ should consider the provident fund alternative.

\subsection{Model Parameters}

The following parameters determine the relative performance of the two types of fund.

$a=$ rate of AIPF pension increase per annum

$b=$ annual after tax rate of return on money invested by the individual

$c=$ rate of salary increase per annum

$d=$ annual rate of return on provident fund investments (before tax)

$\mathrm{L}=$ life expectancy at age 60

$i=$ fraction of salary invested in the provident fund per annum

$\mathrm{s}=$ salary at December 1994

$T=$ transfer value on 1 January 1995

$\mathrm{u}=$ retirement reserve or top-up amount provided by some employers

$k=$ number of years of pensionable service at retirement, assuming individuals retire at 60 years of age

$n=$ number of years to retirement from 1 January 1996.

$\alpha=$ average rate of tax on AIPF pension

$\beta=$ average tax rate applied to provident fund lump sum at retirement

During a given run of the model, the parameters $a, b, c, d, L$ and $i$ have the same values for all individuals (data points), whereas the parameters $T, s, k, n, \alpha$ and $\beta$ depend on the individual.

\subsection{AIPF Calculation}

On retirement a member of the AIPF receives a gratuity and an annuity which depend only on the final salary and the number of years of pensionable service at retirement. At retirement $\mathrm{n}$ years after 1 January 1996 , the final salary is given by $s(1+c)^{n+1}$, the resulting gratuity by 


$$
0.0672 \times k \times s(1+c)^{n+1}
$$

and the starting value of the annuity before tax by

$$
\frac{1}{55} \times k \times s(1+c)^{n+1}
$$

Thus writing $x=\frac{1+a}{1+b}$ and using equation 1 , the after-tax capital equivalent of the AIPF annuity is

$$
\frac{1}{55} \times k \times s(1+c)^{n+1} \times(1-\alpha)\left(\frac{1-x^{2}}{1-x}\right)
$$

Thus the after tax capital equivalent of the AIPF gratuity plus annuity at retirement is

$$
k s(1+c)^{n-1}\left[0.0672+\frac{(1-\alpha)}{55}\left(\frac{1-x^{L}}{1-x}\right)\right]
$$

As mentioned earlier on the power function in $x=\frac{1+a}{1+b}$ decreases when $(b-a)$ increases.

\subsection{Provident fund calculation}

During 1995 the private funds were being set up and registered with the Registrar of Pensions and we assume that pension contributions as well as Retirement Reserve Funds (if any) were paid into the new funds from January 1995. Transfer values were received from the AIPF during 1995. These funds earned interest tax-free at the 1995 bank rate of around $14.6 \%$ before being released by the AIPF. For simplicity it is assumed that all funds earned taxable interest at the yearly rate d during 1995.

Salary increase dates vary between the different institutions. We will assume that increases occur on the 1st day of January each year, that the January pension contribution is invested for 11 months of that calender year, the February contribution for 10 months and so on. Furthermore, we assume for simplicity that amounts invested for less than a full calender year share proportionally in the annual fund growth rate. The 1995 monthly salary contribution to the provident fund is $\frac{i(1+c) s}{12}$, so that the total input to the Provident fund from salary during 1995 is 


$$
\begin{gathered}
\sigma=\frac{i(1+c) s}{12}\left[1+\left(1+\frac{d}{12}\right)+\cdots+\left(1+\frac{11 d}{12}\right)\right] \\
=i(1+c) s\left(1+\frac{11 d}{24}\right)
\end{gathered}
$$

Thus at 31 December 1995 the provident fund value is

$$
V_{0}=(1+d)(T+u)+\sigma
$$

The input from salary increases by a factor $(1+c)$ each year. If $v_{r}$ denotes the value of the provident fund $r$ years later, then

$$
V_{r}=(1+d) V_{r-1}+\sigma(1+c)^{r}, \quad r=1,2, \ldots, n
$$

and hence the value of the provident fund before tax at retirement is

$$
\begin{gathered}
V_{n}=(1+d)^{n}\left(V_{0}+\sigma\left(y+y^{2}+\cdots+y^{n}\right)\right) \text { where } y=\frac{1+c}{1+d} \\
=(1+d)^{n}\left(V_{0}+\sigma y\left(\frac{1-y^{n}}{1-y}\right)\right)
\end{gathered}
$$

The function $y\left(\frac{1-y^{n}}{1-y}\right)$ can be shown to decrease with $(d-c)$ and can be closely approximated by a quadratic in (d-c) for $n \leq 20$.

We now calculate the corresponding after-tax value of the provident fund. The transfer value $T$ is tax-free and there is an additional tax-free amount which is defined in the tax laws on lump sums for the 1996 tax year and may be formulated as follows:

Denote by HAAS, the Highest Average Annual Salary actually earned by the employee during any five consecutive years in the service of the employer during the period of membership of the fund. 
Let $E=\frac{k}{10} \times \min (H A A S, 60000)$, where $\mathrm{k}$ is limited to 50 , then the tax-free portion is given by

$$
C=T+\min \left(\max (120000, k \times 4500), E, V_{n}-T\right)
$$

All our data points satisfy $k>20$ and HAAS $>60000$. In this case $E$ becomes redundant and we have the simpler formula

$$
C=T+\min \left(\max (120000, k \times 4500), V_{n}-T\right)
$$

Tax is paid at the rate $\beta$ on $V_{n}-C$. The after tax value of the provident lump sum is therefore

$$
V_{n}-\beta\left(V_{n}-C\right)
$$

\subsection{Comparison of the Funds}

For each given data point (individual) we calculate the critical value of the Transitional Reserve or Top-up, $u_{c r i t}$, that equates the after-tax AIPF capital equivalent (expression 2 ) and the after-tax provident fund lump sum (expression 3). The ratio $\frac{100 u_{\text {crit }}}{T}$ expresses $u_{c r i t}$ as a percentage of the transfer value and will be referred to as the percentage top-up required to break even at retirement. Due to the tax complications it is not easy to solve for $u_{\text {crit }}$ analyticaily and instead we use a spreadsheet to calculate this value for each data point. Note that instead of targeting $100 \%$ of the AiPF benefit as above, one could, for example, solve

$$
\text { expression (3) }=0.9 \times \text { expression (2) }
$$

for $u$ in order to target $90 \%$ of the AIPF benefit (see section 3.5 ).

\subsection{Parameter Estimation}

The total monthly contribution to the fund is assumed to be $17.5 \%$ of salary spread equally over 12 months, so $\mathrm{i}=0.175$. This value differs slightly between the different institutions. Life expectancy $L$ at age 60 is taken as 21 years. This is the remaining years a female can, on average, expect to live at age 60 . Males have a life expectancy some four years shorter, but will usually have to provide a pension for the surviving 
spouse. The parameter values for $i$ and $L$ have been kept fixed throughout the discussion. The parameters $s, T, k$ and $n$ have known values for each individual and $u=u_{\text {crit }}$ is calculated as indicated in 2.5 .

In order to estimate the average tax rates $\alpha$ and $\beta$, we calculated the average tax rates applicable in 1996 at the top of the various salary scales assuming that there is no other taxable income ${ }^{1}$. The rate $\alpha$ obtained in this manner is assumed constant during the term of the annuity. There is no evidence to suggest that the tax-free amounts are likely to increase over time and hence no such assumption has been made. Due to the so-called tax bracket creep, these estimates are likely to be lower than the actual rates.

The remaining parameters $a, b, c$ and $d$ are assumed to be the same for all individuals and we now proceed to estimate them. The model turns out to be highly sensitive to their values and will be run under various assumptions on these growth rates. For comparison purposes we estimate the historical parameter values. According to Falkena \& Luüs [1], over the past 25 years, CPI inflation has averaged $13.1 \%$ and over this period various investments have offered the following returns

\begin{tabular}{|l|c|}
\hline Money market instruments & $12 \%$ \\
\hline Shares & $19.8 \%$ \\
\hline Bonds & $10.5 \%$ \\
\hline Commercial property & $15.2 \%$ \\
\hline
\end{tabular}

A balanced portfolio favouring shares would therefore have given an annual return of some $18 \%(d=0.18)$.

The AIPF policy regarding pension increases has been to aim for adjustments equal to $70 \%$ of the $\mathrm{CPI}$ inflation rate. This is borne out by pension increase data for the four

${ }^{1}$ Management is likely to assume no other taxable income through lack of data on private income. An individual could take private income into account and derive a more accurate value of $\alpha$ which would be higher than the corporate estimate. 
years from 1992-1995 received from the Department of Finance $(a=0.09)$.

In order to estimate the average salary increase for academics over this period we assume that during the 25 years a lecturer would have progressed from the bottom to the top of the lecturer salary scale resulting in an increase of $13 \%$ compounded annually $(c=0.13)$. This rate of increase happens to coincide with the inflation rate over the same period.

The after-tax rate of return on investments $b$, will be influenced by the types of investment chosen. A cautious individual might opt for fully taxable money market investments which are unlikely to yield an after-tax return of more than $13 \%$. We will assume that investments are professionally done in tax-friendly instruments such as shares or unit trusts, which may yield after-tax returns of about $18 \%$. Bearing in mind that a portion of the investments will necessarily be kept in cash or short-dated deposits an estimate for $b$ is 0.15 .

The set of parameter values specified above will be called the standard set.

It should be noted that our assumption in the model that parameters are constant throughout time is not a real restriction since for every set of time varying parameters, there exists an equivalent set of constant (time averaged) parameters satisfying equations 2 and 3 .

\section{RESULTS}

Each run of the model results in a distribution curve determined by the assumed values of the parameters $a, b, c$ and $d$. Corresponding to each data point in our given data set, the percentage top-up to break even at retirement, $100 \frac{u_{\text {crit }}}{T}$,is calculated and plotted against $n$. As might be expected $100 \frac{u_{\text {crit }}}{T}$ appears from our somewhat limited data to be independent or nearly independent of the values of the parameters $s$ and $k$, so that data points with the same $n$ give almost the same graph point and the fitted curve is a fairly accurate representation of the percentage top-up required to break even at 
retirement for the various age groups. The distribution curve generated by using the standard set of parameter values will be called the standard curve.

\subsection{Parameter sensitivity}

\subsubsection{Individual parameter perturbation}

In fig. 1 we show the effect on the standard distribution curve of perturbations of $\pm 10 \%$ on individual parameters. The results are shown for a $10 \%$ increase in the value of $c$, and $-10 \%$ in the values of $b$ and $d$. The curves $a+, \alpha-$ and $\beta+$ corresponding to similar perturbations in the values of $a, \alpha$ and $\beta$ lie between the standard curve and the curve labelled $b$ - and are not shown in the figure. It is clear that for small values of $n$, the single most sensitive parameter is $b$. For values of $n>6$, the sensitivity ranking in decreasing order is $d, c, b, \beta, a, \alpha$.

Figure 1: Sensitivity of distribution curve to individual parameters

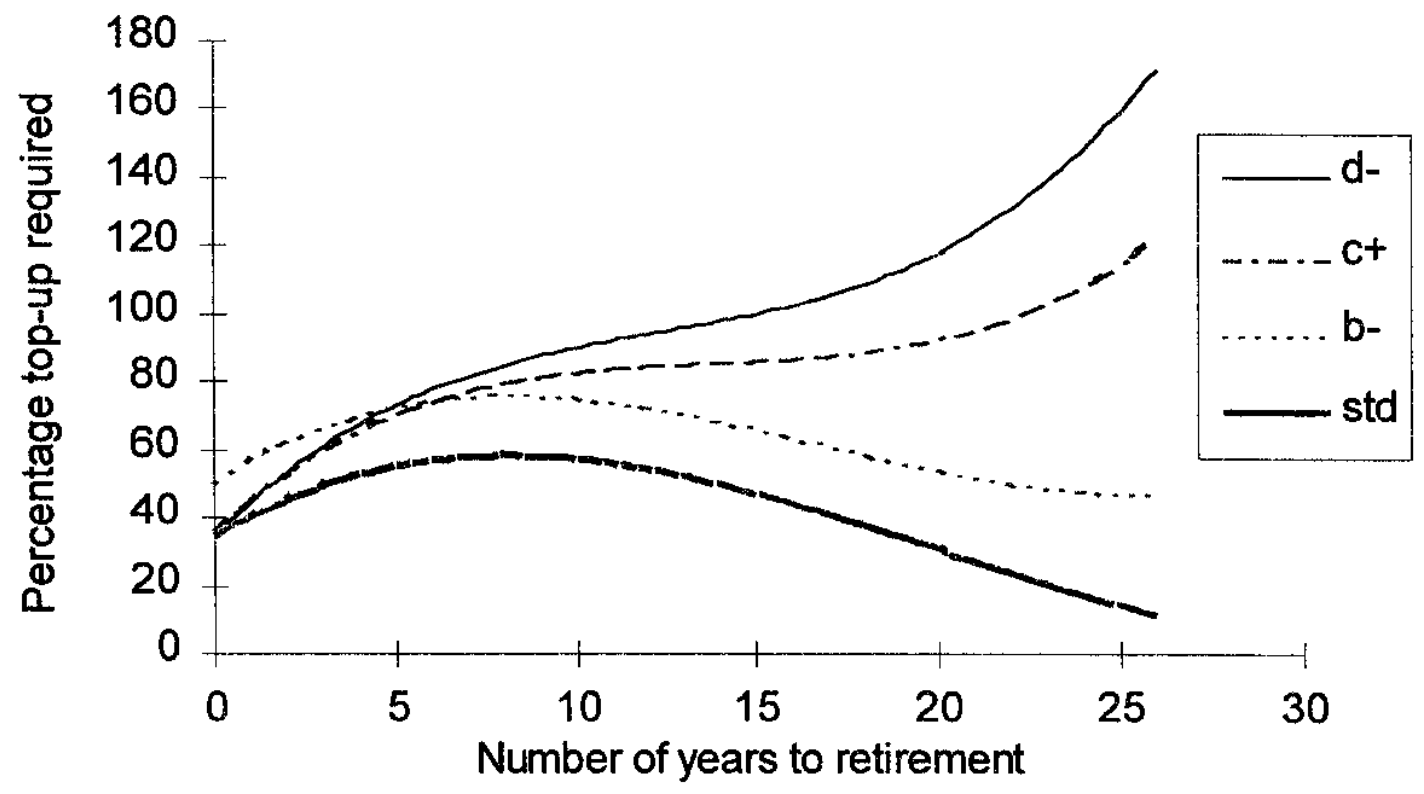

\subsubsection{Sensitivity to different investment growth rates}

Historically the rate of salary increase $c$, has been approximately equal to the rate of inflation and the AIPF has a policy of granting pension increases equal to $70 \%$ of the 
$\mathrm{CPI}$ inflation rate. It is reasonable too, to expect the investment rates $\mathrm{b}$ and $\mathrm{d}$ to move in the same direction. Based on the historical data, with a CPI inflation rate of approximately $13 \%$, we are therefore led to define three possible investment growth scenarios in the table below and in fig. 2 we compare the corresponding model output.

\begin{tabular}{|c|c|c|c|}
\hline & Low & Std & High \\
\hline $\mathrm{a}$ & 0.09 & 0.09 & 0.09 \\
\hline $\mathrm{b}$ & 0.14 & 0.15 & 0.16 \\
\hline $\mathrm{c}$ & 0.13 & 0.13 & 0.13 \\
\hline $\mathrm{d}$ & 0.17 & 0.18 & 0.20 \\
\hline $\mathrm{b}-\mathrm{a}$ & 0.05 & 0.06 & 0.07 \\
\hline $\mathrm{d}-\mathrm{c}$ & 0.04 & 0.05 & 0.07 \\
\hline
\end{tabular}

It is clear that the model is very sensitive to changes in the growth parameters, e.g., the case $n=8$ needs top-ups of $95 \%, 54 \%$ and $22 \%$ respectively under the assumptions of . low growth, standard growth and high growth in order to target $100 \%$ of the AIPF retirement benefit. The actual values of $\frac{100 u_{\mathrm{crt}}}{T}$ are plotted and fourth order polynomial trend lines are fitted to these points. The results suggest that under a low growth scenario, everyone would need a substantial top-up to target $100 \%$ of the AIPF retirement benefits. On the other hand, if high growth rates are assumed on investments, then the top-up can be phased out as shown with no top-up required for values of $\mathrm{n}$ beyond 15 . It is also interesting to note that in all cases, individuals near retirement need a lower percentage top-up than those a little further from retirement as is reflected by the positive slope of all the distribution curves at $n=0$. This is as a result of the substantial tax benefits enjoyed by individuals retiring in the near future. 


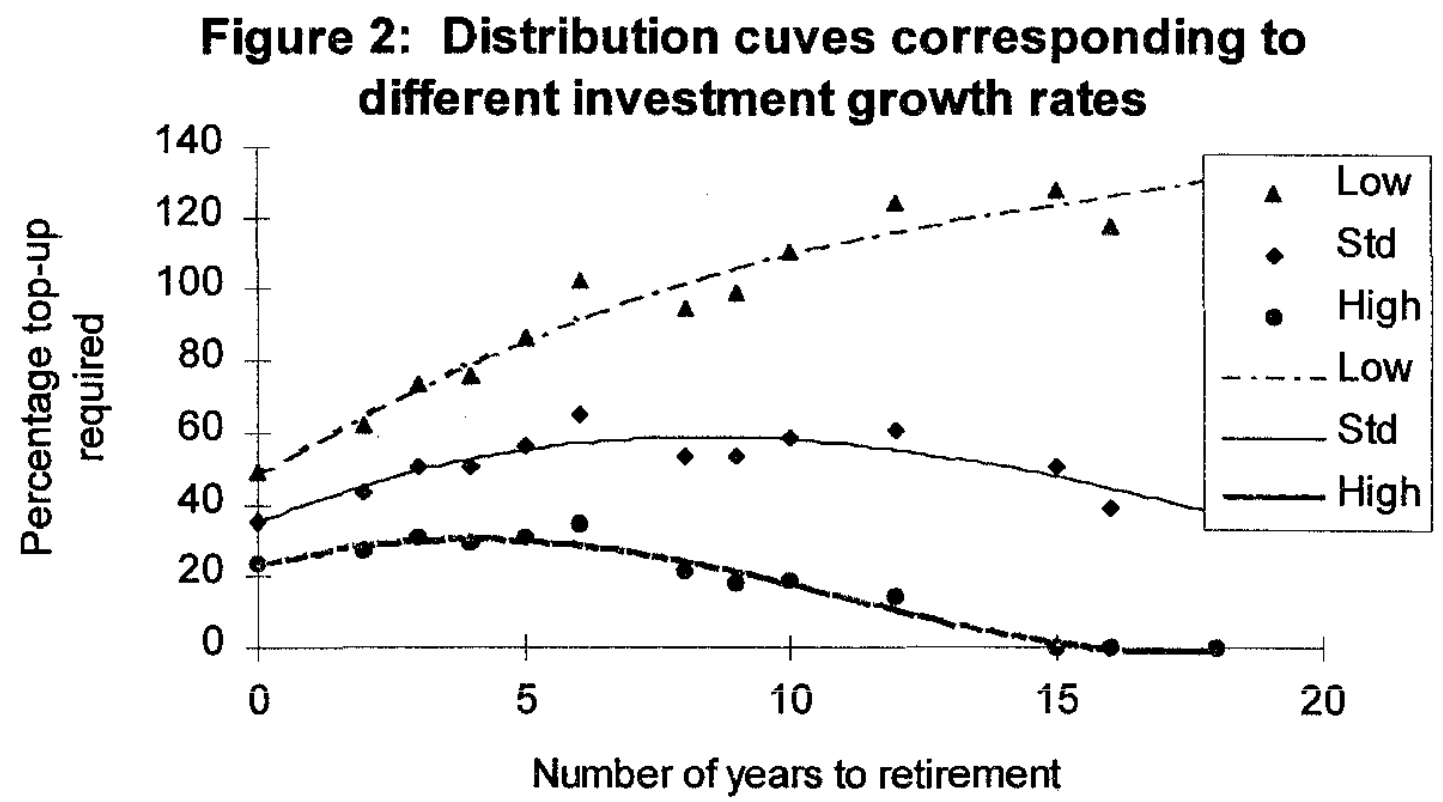

\subsubsection{A possible future scenario of lower inflation}

The historical parameter values were derived during a period of high consumer inflation, high rates of return on investments and relatively high salary increases. During the past three years the inflation rate has been below $10 \%$. During the previous two three year periods July 1992-July 1995 and July 1993-July 1996, the average annual rate of salary increase has been one percentage point above the average inflation rate of $9.5 \%$. We investigate the model output corresponding to different permutations of high/low investment rates and high/low salary increases, assuming that we are entering an extended period of lower inflation.

\begin{tabular}{|l|l|l|l|c|c|c|}
\hline $\mathrm{a}$ & $\mathrm{b}$ & $\mathrm{c}$ & $\mathrm{d}$ & Investment returns & Salary increases & Named curve \\
\hline 0.07 & 0.13 & 0.11 & 0.16 & Low & Low & LL \\
\hline 0.07 & 0.15 & 0.11 & 0.18 & High & Low & HL \\
\hline 0.07 & 0.13 & 0.13 & 0.16 & Low & High & LH \\
\hline 0.07 & 0.15 & 0.13 & 0.18 & High & High & HH \\
\hline
\end{tabular}

Based on an assumed inflation rate of $10 \%$, high/low investment returns correspond to 
real returns of $8 \% / 6 \%$ and high/low salary increases correspond to real rates of $3 \%$ I $1 \%$ respectively. The distribution curves corresponding to the various scenarios defined in the table are shown in fig. 3 . Their similarity to those in fig. 2 is apparent and we will therefore use only the historical parameter set in what follows.

\section{Figure 3: Distribution curves corresponding to a} future scenario of lower inflation

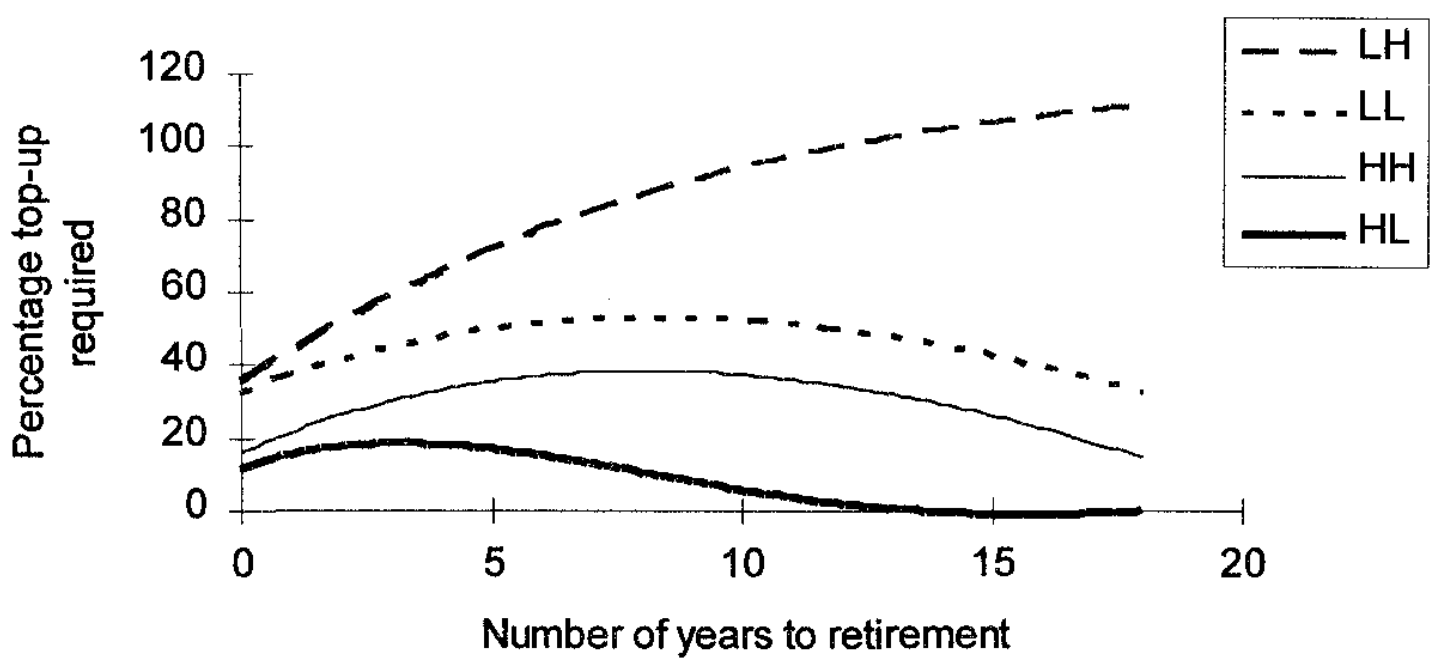

\subsection{Tax calculations}

In our standard model output we are likely to have under-estimated tax rates and especially the tax rate $\alpha$ which applies to the annuity for $L$ years (see section 2.6). In fig. 4 we show the effects of different methods of estimating the tax rates on model output. Firstly we project tax rates into the future as follows: we calculate the average rate of $\operatorname{tax} \beta$ at retirement based on the expected retirement salary (assuming no promotions to a higher salary scale) and apply that to the taxable portion of the provident fund lump sum. The rate $\alpha$ is the average tax rate during the term of the AIPF annuity. We calculate the average tax rate based on the first annuity, the average rate based on the $L$ th annuity and estimate $\alpha$ by taking a value midway between these two rates. Assuming that there is no other taxable income, this calculation should over-estimate 
tax rates as it assumes no tax bracket adjustment over the years. Finally we simply use constant rates of tax $\alpha=0.30$ and $\beta=0.35$ for all data points. These curves are respectively named Std tax, Future tax and Constant tax in fig. 4 . In all cases the standard set of growth rates were used and we assumed that current tax tables remain applicable. In order to avoid confusion we show only the polynomial trend lines fitted to the data points. The figure shows that as expected, the application of the future tax rates leads to the AIPF benefits being relatively less superior and hence lower top-ups are required especially for smaller values of $n$.

The following table shows some selected data points and the corresponding tax rates used.

\begin{tabular}{|c|c|c|c|c|c|c|}
\hline$n$ & 0 & 2 & 4 & 8 & 12 & 16 \\
\hline$s$ & 85920 & 107876 & 127181 & 85920 & 92523 & 92523 \\
\hline$k$ & 34 & 37 & 44 & 37 & 35 & 36 \\
\hline $\operatorname{Std} \beta$ & 0.36 & 0.38 & 0.39 & 0.36 & 0.37 & 0.37 \\
\hline Std $\alpha$ & 0.30 & 0.33 & 0.35 & 0.30 & 0.32 & 0.32 \\
\hline Future $\beta$ & 0.35 & 0.39 & 0.41 & 0.41 & 0.43 & 0.44 \\
\hline Future $\alpha$ & 0.36 & 0.39 & 0.42 & 0.42 & 0.43 & 0.44 \\
\hline Constant $\beta$ & 0.35 & 0.35 & 0.35 & 0.35 & 0.35 & 0.35 \\
\hline Constant $\alpha$ & 0.30 & 0.30 & 0.30 & 0.30 & 0.30 & 0.30 \\
\hline
\end{tabular}


Figure 4: Distribution curves corresponding to different ways of calculating tax rates

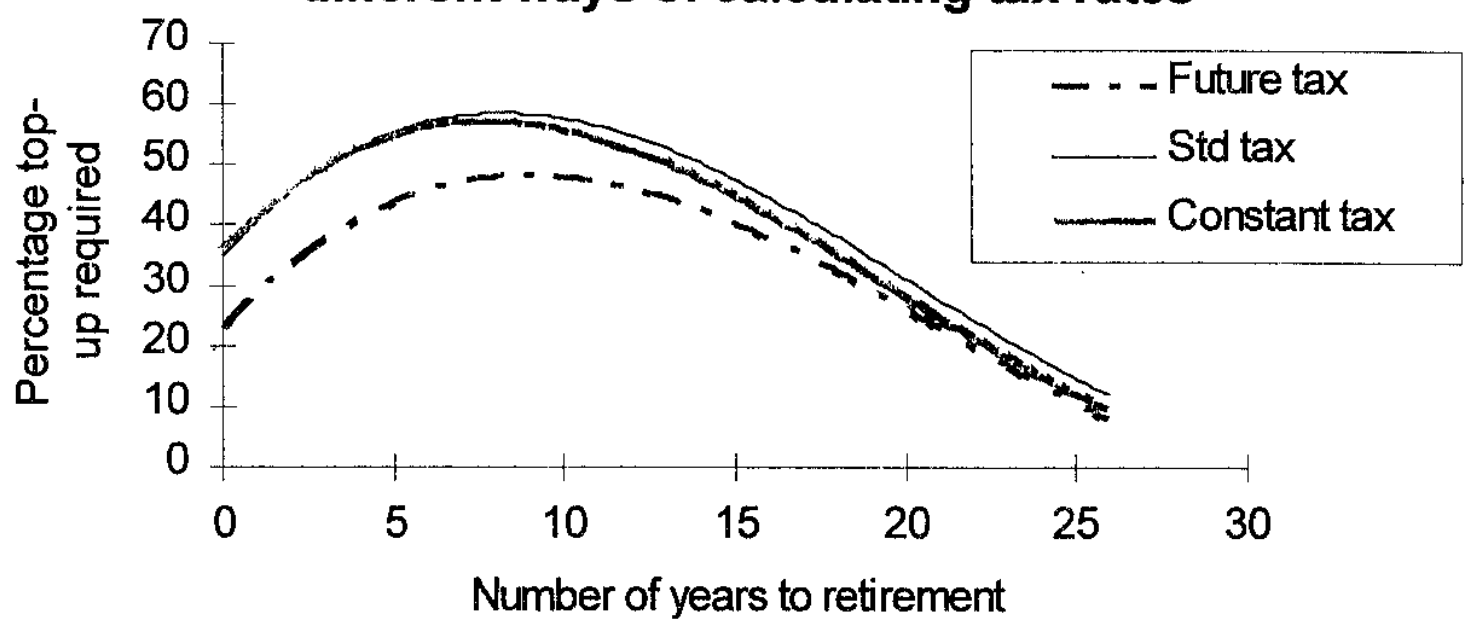

\subsection{Model output compared with actual distribution curves}

From our inquiry addressed to sixteen South African universities, it was learned that six of the fourteen universities who responded, offered a defined contribution provident fund as their only- or major new fund. All these universities provided some form of top-up (retirement reserve) for their members. In fig. 5 we illustrate the shape of these distribution curves by fitting polynomial trend lines to data points supplied by the various institutions. The model output curve shown is our high growth scenario (see section 3.1.2). The university distribution curves $A, B, C$ and $D$, based on models incorporating tax, are similar to distribution curves suggested by our model. Curves B, C and D are similar to model output under the high investment growth scenario and curve $A$ is similar to our standard distribution curve for $n>2$. In the case of university $E$, a model was probably not used and instead it may have been argued that everyone had suffered the same relative loss and available funds were accordingly distributed as shown at the highest affordable level. In the case of university $F$ a model was used but tax was not taken into account, resulting in the anomalous distribution curve shown with its associated huge discontinuity between individuals who retired immediately before and after the new dispensation. [As a matter of interest, if we ignore tax in our model by putting $\alpha=\beta=0$ and take $b-a=0.04, c=0.1$ and $d=0.205$, the distribution curve generated is a reasonable approximation to curve E]. 
Figure 5: Distribution curves used by different

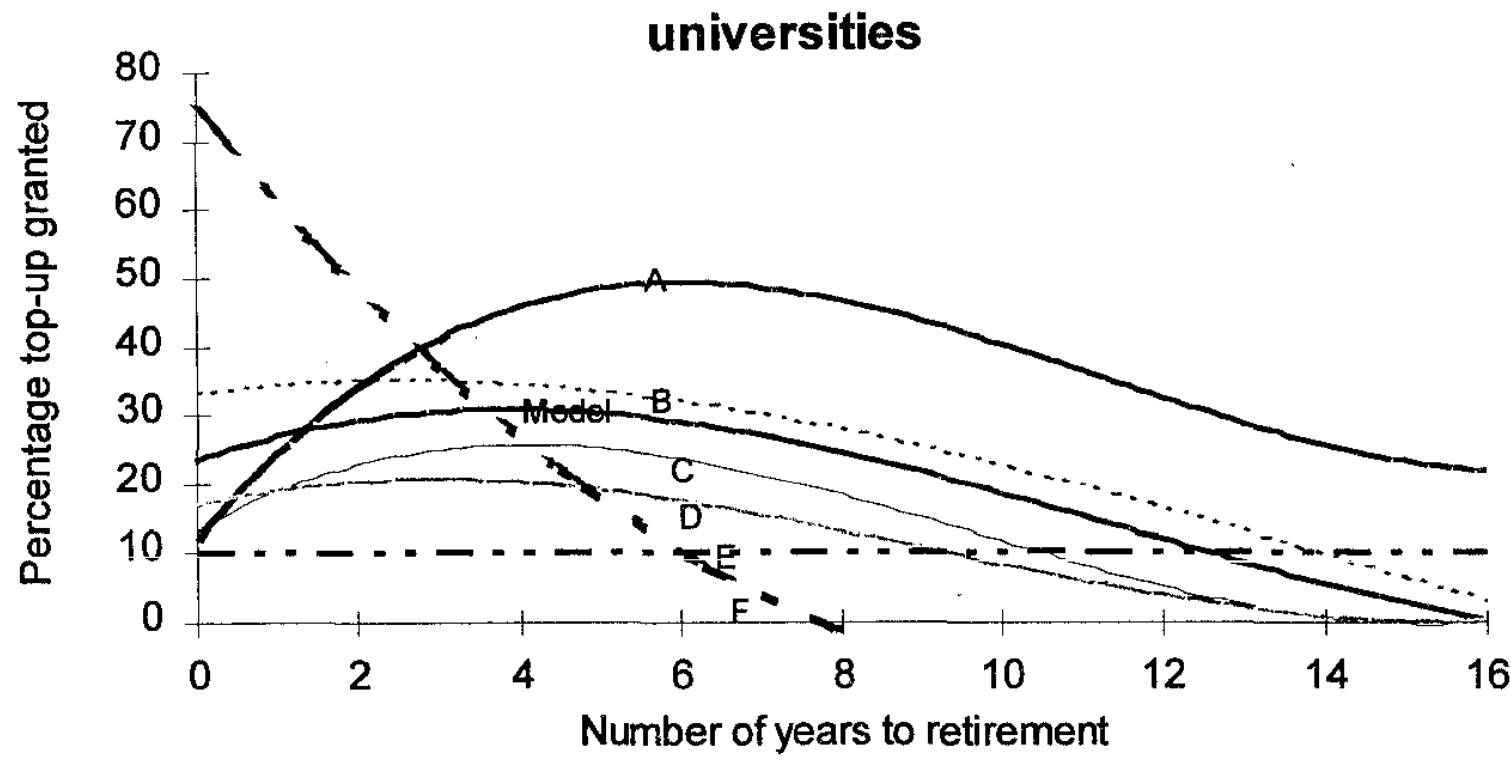

\subsection{The special case of someone retiring on 31 December 1995}

The case $n=0$ merits a special investigation as there are fewer unknowns in this case. The values of $c, d$ and $\beta$ are known for each individual, so that the only variables are $\alpha$ and $b-a$ (see section 2.1). In the following table we show the percentage top-up required in order to break even, $\frac{100 u_{\text {crit }}}{T}$, corresponding to various choices of $\alpha$ and b-a. In addition we calculate the ratio $\frac{T}{T+u_{c r i t}}$. According to our model, $T+u_{\text {crit }}$ is the amount that an individual should have received in January 1995 in order to equal the after-tax AIPF benefits. Since T is the actual amount transferred from the AIPF $\frac{T}{T+u_{\text {crit }}}$ could therefore be said to measure the funding level of the AIPF according to orf model. This is a different definition of funding level from that used by the AIPF.

\begin{tabular}{|c|c|c|c|c|c|c|}
\hline$\alpha$ & 0.3 & 0.36 & 0.3 & 0.36 & 0.3 & 0.36 \\
\hline b-a & 0.04 & 0.04 & 0.06 & 0.06 & 0.08 & 0.08 \\
\hline $\begin{array}{c}\text { Percentage top-up required to } \\
\text { break even }\end{array}$ & 52.3 & 38.5 & 30.4 & 18.5 & 13.0 & 3.8 \\
\hline$T /\left(T+u_{\text {crit }}\right)$ & 66 & 72 & 77 & 84 & 88 & 96 \\
\hline
\end{tabular}


From the table it is seen that, according to our model, the funding level of the AIPF was around $70 \%, 80 \%$ or $90 \%$, corresponding to $b$-a values of $0.04,0.06$ or 0.08 respectively, which is higher than the $60 \%$ funding level as determined by the AIPF .

\subsection{The model as a decision tool}

The model may be used by an individual to choose between the two options and may also be used by an institution to decide on a fair method of distributing available top-up funds.

The individual has to decide on a likely set of growth parameter values and calculate applicable tax rates. The model may then be used to calculate the corresponding top-up $u_{\text {crit }}$ required to equal $100 \%$ of the after-tax AIPF benefits. This must then be compared with the actual top-up offered. An individual may well be prepared to accept a top-up which is less than the actual top-up offered because of certain advantages of a provident fund such as mobility and control of personal funds at retirement.

The institution will have a fixed amount of money available for distribution as top-up funds. The institution will choose its parameter values and calculate $u_{\text {crit }}$ for each individual. The sum of $u_{\text {crtt }}$ over all individuals is the total top-up required. In the event that this sum exceeds the funds available for top-up, the institution should then determine the highest affordable targeting level. This will result in a top-up distribution that is as fair as possible when factors not explicitly modelled such as mobility and financial control are ignored. In figure 6 we show that by targeting $90 \%$ of the AIPF benefit, a substantially reduced amount would be needed for topping-up. For the data points used in our model and using the standard growth parameters, the saving amounts to $43 \%$. The saving for the institution will depend on the age distribution of its members. 
Figure 6: Targeting a percentage of the AIPF benefit

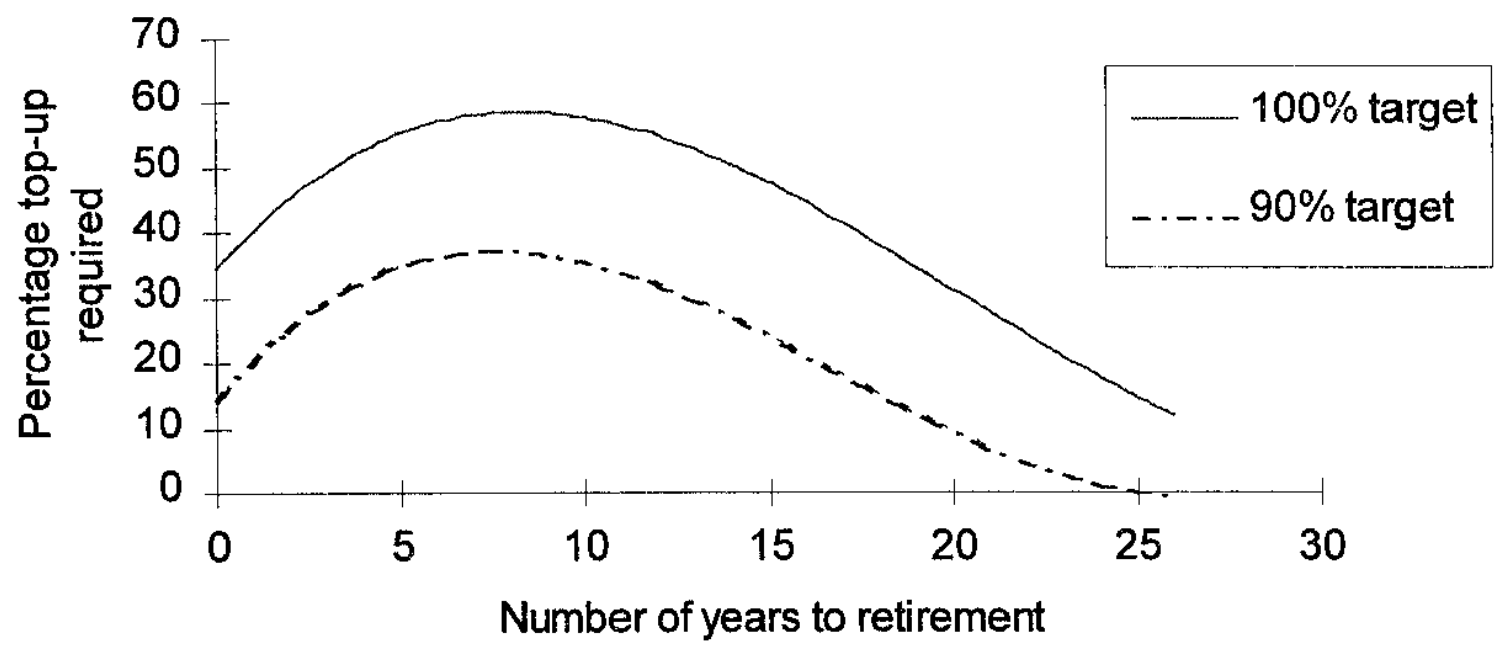

\section{CONCLUSION}

We have formulated a model that can be used to assist an individual in making a choice between a defined benefit pension fund and a defined contribution provident fund. In addition it can be used by an institution in deciding on a fair distribution of available top-up funds.

All the distribution curves increase with $\mathbf{n}$ initially. The distribution curves corresponding to the standard and high growth scenarios reach a maximum for $n$ somewhere between 3 and 8 and then decrease, eventually reaching zero.

The model is extremely sensitive to parameter variation as figures 1,2 and 3 illustrate. By assuming the standard growth scenario and targeting $100 \%$ of the AIPF benefits, substantial top-up is needed for individuals within 25 years of retirement. Under the low growth scenario, the percentage top-up required to break even increases with $\mathrm{n}$. In the high growth scenario, the percentage level of top-up required for after-tax equivalence between the two funds, drops to below $20 \%$ for individuais with more than 8 years to retirement and can be phased out for individuals with 15 years or more to retirement (fig. 2). 
The university distribution curves $A, B, C$ and $D$ (fig. 5), based on models incorporating tax, are similar to distribution curves suggested by our model. Curves B, C and D are similar to model output under the high investment growth scenario ; alternatively, these curves can be approximated by model output generated by taking parameter values close to the standard set and targeting less than $100 \%$ of the AIPF benefit. For $n$ greater than 2, curve $A$ is similar to the standard curve (fig. 2).

Model output is not very sensitive to the choice of method used to estimate the tax rates $\alpha$ and $\beta$ (see fig. 4), but it is imperative to compare the after-tax benefits of the two types of fund as completely different results are obtained if tax is ignored.

\section{ACKNOWLEDGMENTS}

The authors would like to thank the universities and actuaries who responded to their requests for information about pension and provident funds and gratefully acknowledge research support from the University of Natal and the FRD.

\section{REFERENCES}

[1] H. B. FALKENA and C. W. LUÜS, Personal Wealth \& Financial Independence, Southern Publishers (Pty) Ltd, Halfway House (1994).

\section{APPENDIX}

Let $F(a, b)=\frac{1-x^{21}}{1-x}$ where $x=\frac{1+a}{1+b}$. We assume that

$$
0.12 \leq b \leq 0.17, \quad 0.03 \leq b-a \leq 0.08
$$

Let $\left(a_{1}, b_{1}\right)$ and $\left(a_{2}, b_{2}\right)$ be two points satisfying (4) and such that $b_{1}-a_{1}=b_{2}-a_{2}=w$. We show that 


$$
\frac{\left|F\left(a_{1}, b_{1}\right)-F\left(a_{2}, b_{2}\right)\right|}{F\left(a_{1}, b_{1}\right)}<0.52 w<0.042 .
$$

Let $f(x)=\frac{1-x^{21}}{1-x}=1+x+x^{2}+\cdots+x^{20}$. For $x>0, f$ and its first and second derivatives are clearly positive and are increasing functions of $x$. Writing $x=1-\frac{w}{1+b}$ where $w=b-a$ and restricting $b-a$ to the range in (4), we obtain

$$
1-\frac{0.8}{1.12} \leq x \leq 1-\frac{0.03}{1.17}
$$

Hence

$$
\begin{gathered}
\left|F\left(a_{1}, b_{1}\right)-F\left(a_{2}, b_{2}\right)\right| \\
\leq f\left(1-\frac{w}{1.17}\right)-f\left(1-\frac{w}{1.12}\right) \\
\leq\left(\frac{w}{1.12}-\frac{w}{1.17}\right) f^{\prime}\left(1-\frac{0.03}{1.17}\right)<5.82 w
\end{gathered}
$$

Thus

$$
\begin{gathered}
\frac{\left|F\left(a_{1}, b_{1}\right)-F\left(a_{2}, b_{2}\right)\right|}{F\left(a_{1}, b_{1}\right)} \\
\leq \frac{5.82 w}{f\left(1-\frac{0.08}{1.12}\right)} \\
<0.53 w \leq(0.53)(0.08)<0.043
\end{gathered}
$$

